\title{
Differential Diagnosis and Management Issues of Idiopathic Angiooedema and their Resolution
}

\author{
Andrea Zanichelli, Marta Mansi, Maddalena A. Wu, Giulia Azin, Marco Cicardi* \\ Department of Biomedical and Clinical Sciences "L. Sacco" University of Milan and Ospedale L. Sacco Milan, Italy
}

\begin{abstract}
Angiooedema is a local and self-limiting swelling of the subcutaneous and sub mucosal tissues, produced by vasoactive peptides that temporary increase the vascular permeability.

It is recognized that recurrent angiooedema exposes patients to the risk of fatalities and reduced quality of life, being in some circumstances associated with a critical condition.

Angiooedema can occur with or without wheals. The first symptom is urticaria, the second is a distinct nosologic entity. In absence of an identifiable cause, recurrent angiooedema without wheals can be defined as idiopathic and marked "idiopathic histaminergic angiooedema" when it is responsive to anti histamine treatment, and "idiopathic non-histaminergic angiooedema" when it is not. Furthermore, idiopathic non-histaminergic angiooedema can be diagnosed as hereditary or sporadic by family history.
\end{abstract}

In this review, we summarize the approaches to diagnose and treat different forms of idiopathic angiooedema.

Keywords: angiooedema, idiopathic, C1 inhibitor, factor XII, bradykinin, tranexamic acid

Received: 10 March 2015 / Accepted: 18 April 2015

\section{INTRODUCTION}

The word idiopathic derives rom Greek ' $\delta$ เoc (idios) "one's own" and rá $\theta$ oc (pathos) "suffering". It is used by physicians when they cannot define the origin of a specific suffering any better than saying that it comes from itself.

In some cases, recurrent angiooedema can expose patients to the risk of fatalities and therefore can be considered as a critical condition that requires prompt diagnosis and intervention.

In this paper, idiopathic angiooedema refers to all forms of angiooedema with unknown etiology and pathogenesis. Angiooedema is a local, self-limiting oedema of the deep layers of the subcutaneous and submucosal tissues.

It occurs when inflammatory mediators bind specific receptors on the surface of endothelial cells. This binding activates the nitric oxide pathway and induces phosphorylation of the intracellular moiety of specific transmembrane proteins, collectively identified as tight and adherens junctions. These proteins occlude the gap between vascular endothelial cells and upon phosphorylation, pull apart adjoining cells, increasing vascular permeability [1]. Bradykinin, the best-characterized mediator of angiooedema, is generally considered to exert its effect on vaso-permeability through this series of events [2].

Temporary cutaneous deformities, oral and upper airway oedema and oedema of the gastrointestinal mucosa causing abdominal pain are the clinical equivalents of angiooedema. The increase in vascular permeability and its attending symptoms, last from a few hours up to five days and vanish without persisting damage. Angiooedema is symptom of urticaria when occurs with wheals, while angiooedema without wheals is an independent nosologic entity encompassing different types. The first classification of recurrent angiooedema without wheals [3] was published in 2014. This classification excludes allergic or para-allergic angiooedema on the basis that they appear in close temporal relation

\footnotetext{
* Correspondence to: Marco Cicardi, Via G.B. Grassi 74, 20157 Milano, Italy; e-mail: marco.cicardi@unimi.it
} 
with exposure to specific factors and thus are not per se recurrent.

The 2014 classification distinguishes seven forms of recurrent angiooedema. Two are related to the deficiency of $\mathrm{C} 1$ inhibitor, either hereditary $(\mathrm{C} 1-\mathrm{INH}-$ $\mathrm{HAE}$ ) or acquired (C1-INH-AAE). Less than ten years ago, mutations in factor XII (FXII) gene, segregating with the symptoms of angiooedema, were identified in families with angiooedema but lacking any C1-INH (FXII-HAE) deficiency. Another form of acquired angiooedema is related to treatment with the angiotensin converting enzyme inhibitors ACEI-AAE. Thus, four out of the seven different angiooedema have recognizable etiology, three "come from themselves" and can be defined as idiopathic [4-7].

\section{DIFFERENTIAL DIAGNOSIS OF IDIOPATHIC}

\section{ANGIOOEDEMA}

Idiopathic angiooedema can be distinguished based on clinical presentation and on their response to therapy. Careful history taking can identify angiooedema symptoms within a family. The physician, when enquiring about angioedema, should not limit his/her questions to cutaneous oedema, but should also include questions likely to disclose recurrent abdominal pain without identified origin, symptoms of laryngeal oedema and death in the family from sudden from acute respiratory distress, all of which can be presenting symptoms of angiooedema. On the other hand, symptoms of urti- caria should not always be identified with a diagnosis of angiooedema. Distinguishing between angiooedema and wheals may not always be straight forward. Figure 1 details the facial symptoms in a patient with urticaria, and with C1-INH-HAE. These present as two distinct entities when directly compared, but can easily appear indistinguishable when patients try to give a description of these symptoms in relatives. In order to avoid an erroneous diagnosis of hereditary angioedema as opposed to urticaria, the concomitant presence of itching and erythematous wheals on the trunk and limbs should be looked for in the patient or reported in the history. Symptom location slightly changes in patients with different types of angioedema and it has been reported in the literature that abdominal symptoms are detected more often in hereditary forms of angiooedema of unknown origin (U-HAE) than in patients with idiopathic non-histaminergic acquired angiooedema (InH-AAE) [8].

A major criterion in the differential diagnosis of idiopathic angiooedema is the response of the condition to therapy. It has been stated above, that angiooedema is due to the release of a vasodilating mediator. Clinical experience demonstrates that blocking $\mathrm{H}_{1}$-histamine receptorswith specific antagonists such as $\mathrm{H}_{1}$-antihistamines, prevents the recurrence of angiooedema in some patients. Such angiooedema are defined as histaminergic, as it is assumed that histamines the primary mediator [9]. On the other hand, drugs that specifically block bradykinin B2 receptors effectively revert symptoms in
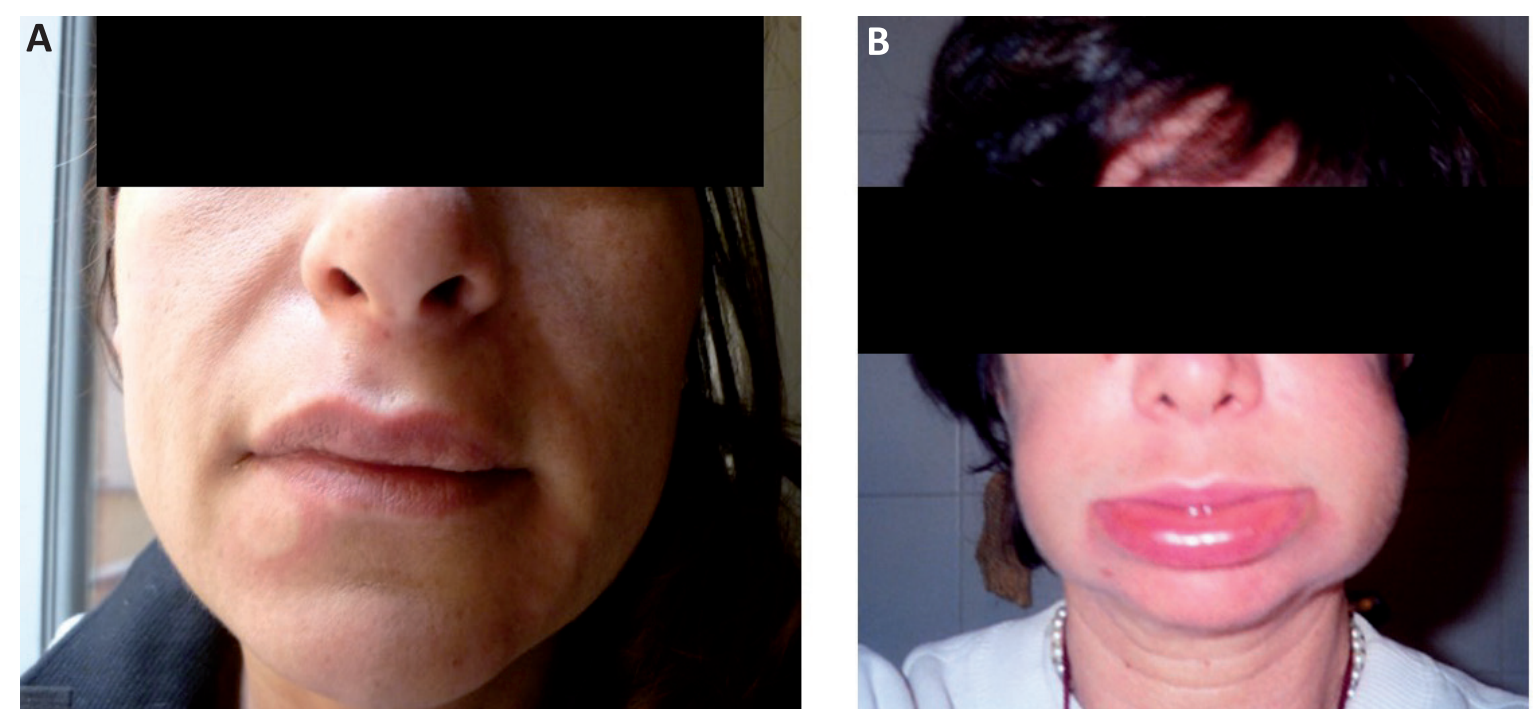

Figure 1. Panel A, angiooedema of the lips in a patient with chronic urticaria. Panel B, angiooedema of the lips in a patient with hereditary angiooedema due to $\mathrm{C} 1$ inhibitor deficiency. Note that in chronic urticaria the angiooedema tend to remain circumscribed while in the hereditary form it spreads to the surrounding tissues 
C1-INH-HAE, suggesting that this is a bradykininergic form of angiooedema [10]. Although no controlled study has been conducted which evaluated the efficacy of $\mathrm{H}_{1}$-antihistamines in angiooedema, these drugs are generally considered to be indicative of chronic urticaria. Extrapolating from this consensus, they are successfully used as a preventive measure in the treatment of chronically recurrent angiooedema [11]. Response to $\mathrm{H}_{1}$-antihistamines given prophylactically can be used to identify patients with idiopathic histaminergic angioedema (IH-AAE). The highest dose of $\mathrm{H}_{1}$-antihistamine necessary to rule out IH-AAE is not univocally accepted. The standard recommendation $[3,12]$ is to prescribe up to four times the recommended dose for chronic urticarial, though it has been shown that patients unresponsive to twice the registered dose, seldom if ever responded to further increases [13].

Figure 2 summarizes the position; when a patient has recurrent angiooedema without wheals and appropriate workup excludes causative agents or conditions, angiooedema is defined as idiopathic and accompanied by a relevant family history, it is diagnosed as HAE of unknown origin (U-HAE). In the absence of a relevant family history the idiopathic angiooedema is classified as histaminergic (IH-AAE) or non histaminergic (InHAAE) according to the response to $\mathrm{H}_{1}$-antihistamines. When histamine is excluded as a mediator consideration should be given to a diagnosis of bradykininergic angioedema, though it should be understood that only a few studies support bradykinin as a mediator of idiopathic angiooedema [14] and subgroups with different pathogenesis should not be excluded. At present, the consensus is that only C1-INH-related and ACEIrelated angiooedema can be considered bradykinin mediated.

\section{MANAGEMENT OF IDIOPATHIC}

\section{ANGIOOEDEMA}

Idiopathic angiooedema that does not respond to $\mathrm{H}_{1}$ anti-histamine is frequently treated with drugs which have proved effective in the treatment of $\mathrm{C} 1-\mathrm{INH}$ HAE. This drug can be used, either in the treatment of acute episodes, or as a prophylactic treatment. Most of the evidence to validating the response of idiopathic angioedema to therapies is reported in case reports and

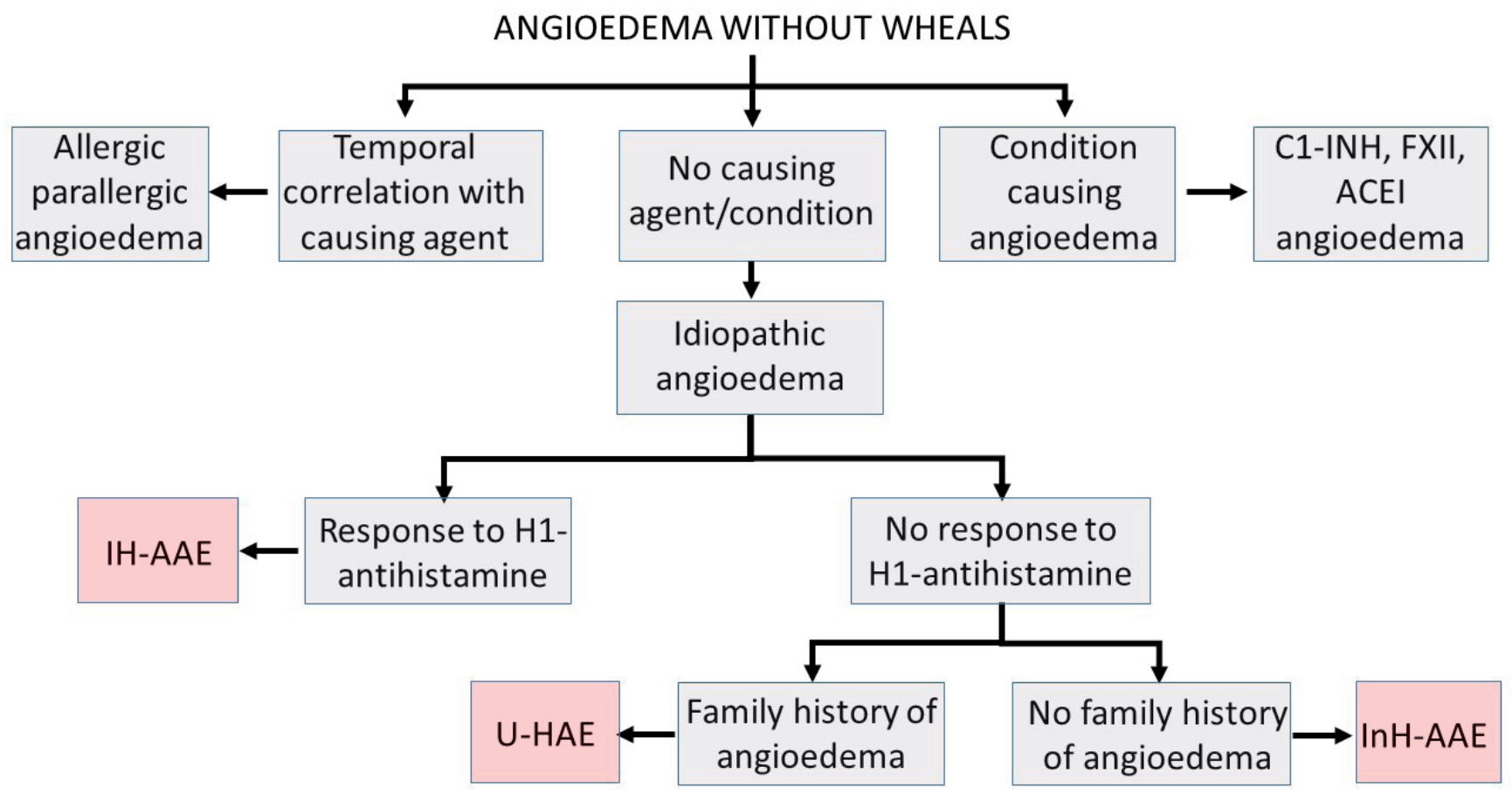

Figure 2. Algorithm for the diagnosis of idiopathic angiooedema starting from angiooedema recurring in absence of wheals. The first step is to exclude that angiooedema occurs in a temporal correlation with exposure to a specific agent as in allergic/pseudoallergic angiooedema. The workup should then exclude identified causes of angiooedema as $\mathbf{C 1}$ inhibitor deficiency, mutations in factor XII, treatment with angiotensin converting enzyme inhibitors. In absence of causative agents or conditions, the angiooedema is idiopathic. Within this group it has be define if it is hereditary (HAE) or acquired (AAE) and, within acquired, if it responds to $\mathrm{H}_{1}$-antihistamine (IH-AAE) or if it does not (InH-AAE). 
small case series. No controlled study or observational prospective study has been identified in a recent literature research.

It is recognized that recurrent angiooedema exposes patients to the risk of fatalities and reduced quality of life. C1-INH-HAE has been assessed in terms of number of recurrences, number of disease related deaths and economic impact [15-20]. Similar reports for idiopathic angiooedema are not available, nevertheless it is known that the symptoms are analogous and deaths can occur $[9,21,23]$. Hence, there is need for effective treatment aimed at reducing morbidity and avoiding mortality. The estimated mortality of C1-INH-HAE, in absence of specific diagnosis and treatment, is about $25 \%$. Nevertheless, specific drugs are available for the treatment of for life-threatening attacks to patients with C1-INH-HAE. The same cannot be done for idiopathic angiooedema. The first line approach for any patient with angiooedema is corticosteroids, anti $\mathrm{H}_{1}$ histamine and epinephrine in the presence of laryngeal involvement [24]. This approach is suitable for conditions originating from mast-cell activation and it is indeed justified since angiooedema of this origin is certainly the most common. However, general experience indicates this approach to be scarcely effective in non-histaminergic idiopathic angiooedema. Solid data confirming this statement are absent and evidence of inefficacy are grounded in a patient's retrospective history. We have adopted the policy to continue recommending with our patients, corticosteroids, $\mathrm{H}_{1}$-antihistamine and epinephrine (if necessary) as first choice for acute treatment. When this approach is confirmed to be ineffective, bradykinin targeted drugs are considered, this approach being based on several studies [2533]. These drugs have been indicated for C1-INH-HAE and include plasma derived and recombinant C1-INH, a recombinant inhibitor of plasma kallikrein and the antagonist of bradykinin receptors [10,24-37]. Fresh frozen plasma, used to replace $\mathrm{C} 1-\mathrm{INH}$ when specific concentrates are not available, can also be an option to replace an unidentified deficiency leading to bradykinin release.

Controlled studies which provided the evidence that is needed to appropriately treat these differing entities, starting with an initial effort of classifying angiooedema within specific groups [3] is called for.

The same problem also applies to prophylactic treatment of the disease. This approach, aimed at administering treatment in absence of signs of angiooedema in order to prevent its occurrence, may result in a continuous lifelong therapy. Embarking on such a course of treatment requires careful risk benefit evaluation, weighting efficacy and side effects and consideration of the impact on the quality of life. None of these assessment relays on specific tools and the decision relies on the physicians' clinical judgment and the patients' informed evaluation. As a general recommendation, prophylaxis is considered when patients experience two or more attacks per month that impact on their daily activities. Choosing the drug in the absence of a recognized aetiology should be made after first undertaking an epidemiologic evaluation. Idiopathic angiooedema mediated by histamine appear to be more common and it is therefore recommended to start with a second-generation $\mathrm{H}_{1}$-antihistamines such as azelastine, bilastine, cetirizine, desloratadine, ebastine, fexofenadine, levocetirizine, loratadine or mizolastine. A dose, double that recommended for allergic diseases, increasing to three times in presence of a partial response, has been recommended. There are no rules for dose tapering in responsive patients, and the view has been expressed in the literature, that it is better not to consider any reduction before three months of successful treatment. When anti $\mathrm{H}_{1}$-histamine fails, tranexamic acids should be considered as the first choice for prophylaxis of these non-histaminergic idiopathic angiooedema $[9,25,32,38]$. Efficacy of this drug seems to cover also hereditary forms with unknown pathogenesis [22]. Doses up to three grams per day can be used, tapering to the effective dose according to the achieved clinical response. Thrombotic risk should be assessed before prescribing this treatment, due to its clot stabilizing activity [39].

Little experience has been reported in the literature on the efficacy of the anti-IgE omalizumab in idiopathic angiooedema [40]. This, as with other treatment used in histamine resistant chronic urticarial, has been considered for non-histaminergic angiooedema, but no reported recommendation for their use appear in the literature.

\section{CONCLUSIONS}

Recurrent angiooedema is a condition that can expose patients to a critical clinical condition or even death. The prompt diagnosis and intervention is therefore crucial in these cases, in order to prevent the development of serious complications. In absence of specific 
Available online at: www.jccm.ro

diagnosis and treatment, the estimated mortality of C1-INH-HAE, is as high as $25 \%$, underlining the need for a correct treatment of the life-threatening attacks to patients with C1-INH-HAE. Furthermore, prophylaxis regimens should be considered whenever the patients experience two or more attacks per month, and should be adapted to the specific form of angiooedema.

The studies on the mechanisms of in vivo activation of the contact system are expected to clarify the pathogenesis of hereditary angioedema associated with FXII mutations and possibly the mechanisms involved in some idiopathic angioedema. This research should end up in target for diagnosing, monitoring and treating these patients, having a great potential to be translated into a better life for patients.

\section{ACKNOWLEDGMENTS}

The work has been supported by Fondazione Telethon grant n. GGP08223.

\section{- CONFLICT OF INTEREST}

\section{None}

\section{REFERENCES}

1. Bravi L, Dejana E, Lampugnani MG. VE-cadherin at a glance. Cell Tissue Res. 2014;355(3):515-22.

2. Orsenigo F, Giampietro C, Ferrari A et al. Phosphorylation of VEcadherin is modulated by haemodynamic forces and contributes to the regulation of vascular permeability in vivo. Nat Commun. 2012;3:1208.

3. Cicardi M, Aberer W, Banerji A et al. Classification, diagnosis, and approach to treatment for angiooedema: consensus report from the Hereditary Angiooedema International Working Group. Allergy. 2014;69(5):602-16.

4. Bork K, Barnstedt SE, Koch P, Traupe H. Hereditary angiooedema with normal C1-inhibitor activity in women. Lancet. 2000;356(9225):213-7.

5. Dewald G, Bork K. Missense mutations in the coagulation factor XII (Hageman factor) gene in hereditary angiooedema with normal C1 inhibitor. Biochem Biophys Res Commun. 2006;343(4):1286-9.

6. Cichon S, Martin L, Hennies HC et al. Increased activity of coagulation factor XII (Hageman factor) causes hereditary angiooedema type III. Am J Hum Genet. 2006;79(6):1098-104.

7. Bork K, Kleist R, Hardt J, Witzke G. Kallikrein-kinin system and fibrinolysis in hereditary angiooedema due to factor XII gene mutation Thr309Lys. Blood Coagul Fibrinolysis.
The Journal of Critical Care Medicine 2015;1(2) • 59

2009;20(5):325-32.

8. Mansi M, Zanichelli A, Coerezza A et al. Presentation, diagnosis and treatment of angiooedema without wheals: retrospective analysis of a cohort of 1058 patients. J Intern Med. 2015;277(5):585-93.

9. Cicardi M, Bergamaschini L, Zingale LC, Gioffre D, Agostoni A. Idiopathic nonhistaminergic angiooedema. Am J Med. 1999;106(6):650-4.

10.Cicardi M, Banerji A, Bracho F et al. Icatibant, a new bradykininreceptor antagonist, in hereditary angiooedema. N Engl J Med. 2010;363(6):532-41.

11.Kaplan AP. Angiooedema. World Allergy Organ J. 2008;1(6):10313.

12.Zuberbier T. A Summary of the New International EAACl/ GA2LEN/EDF/WAO Guidelines in Urticaria. World Allergy Organ J. 2012;5 Suppl 1:S1-5.

13.Zingale LC, Beltrami L, Zanichelli A et al. Angiooedema without urticaria: a large clinical survey. CMAJ. 2006;175(9):1065-70.

14.Nussberger J, Cugno M, Cicardi M. Bradykinin-mediated angiooedema. N Engl J Med. 2002;347(8):621-2.

15.Bygum AM, Aygoren-Pursun EM, Caballero TMP et al. The hereditary angiooedema burden of illness study in Europe (HAEBOIS- Europe): background and methodology. BMC Dermatol. 2012;12:4.

16. Wilson DA, Bork K, Shea EP, Rentz AM, Blaustein MB, Pullman WE. Economic costs associated with acute attacks and longterm management of hereditary angiooedema. Ann Allergy Asthma Immunol. 2010;104(4):314-20.

17.Lumry WR, Castaldo AJ, Vernon MK, Blaustein MB, Wilson DA, Horn PT. The humanistic burden of hereditary angiooedema: Impact on health-related quality of life, productivity, and depression. Allergy Asthma Proc. 2010;31(5):407-14.

18. Lin RY, Shah SN. Increasing hospitalizations due to angiooedema in the United States. Ann Allergy Asthma Immunol. 2008;101(2):185-92.

19.Zanichelli A, Vacchini R, Badini M, Penna V, Cicardi M. Standard care impact on angiooedema because of hereditary $\mathrm{C} 1$ inhibitor deficiency: a 21-month prospective study in a cohort of 103 patients. Allergy. 2011;66(2):192-6.

20.Bork K, Hardt J, Witzke G. Fatal laryngeal attacks and mortality in hereditary angiooedema due to C1-INH deficiency. J Allergy Clin Immunol. 2012;130(3):692-7.

21.Marcos C, Lopez Lera A, Varela S, Linares T, Alvarez-Eire MG, Lopez-Trascasa M. Clinical, biochemical, and genetic characterization of type III hereditary angiooedema in 13 Northwest Spanish families. Ann Allergy Asthma Immunol. 2012;109(3):195-200.

22.Vitrat-Hincky V, Gompel A, Dumestre-Perard C et al. Type III hereditary angio-ooedema: clinical and biological features in a French cohort. Allergy. 2010;65(10):1331-6.

23.Bork K. Hereditary angiooedema with normal C1 inhibitor. Immunol Allergy Clin North Am. 2013;33(4):457-70. 
60 - The Journal of Critical Care Medicine 2015;1(2)

24.Bernstein JA, Lang DM, Khan DA et al. The diagnosis and management of acute and chronic urticaria: 2014 update. J J Allergy Clin Immunol. 2014;133(5):1270-7.

25.Wintenberger C, Boccon-Gibod I, Launay D et al. Tranexamic acid as maintenance treatment for non-histaminergic angiooedema: analysis of efficacy and safety in 37 patients. Clin Exp Immunol. 2014;178(1):112-7.

26. Ozturk $A B$, Kocaturk $E$. Omalizumab in recurring larynx angiooedema: a case report. Asia Pac Allergy. 2014;4(2):129-30.

27.Saule C, Boccon-Gibod I, Fain O et al. Benefits of progestin contraception in non-allergic angiooedema. Clin Exp Allergy. 2013;43(4):475-82.

28. Montinaro V, Loizzo G, Zito A, Castellano G, Gesualdo L. Successful treatment of a facial attack of angiooedema with icatibant in a patient with idiopathic angiooedema. Am J Emerg Med. 2013;31(8):1295.e5-6.

29.Bork K, Wulff K, Witzke G, Stanger C, Lohse P, Hardt J. Antihistamine-resistant angiooedema in women with negative family history: estrogens and F12 gene mutations. Am J Med. 2013;126(12):1142.e9-14.

30.Berry A, Firszt R. Successful treatment of idiopathic angiooedema with ecallantide. J Allergy Clin Immunol Pract. 2013;1(3):297-8.

31.Del Corso I, Puxeddu I, Sardano E et al. Treatment of idiopathic nonhistaminergic angiooedema with bradykinin B2 receptor antagonist icatibant. Ann Allergy Asthma Immunol. 2012;108(6):460-1.

32.Du-Thanh A, Raison-Peyron N, Drouet C, Guillot B. Efficacy of
Available online at: www.jccm.ro

tranexamic acid in sporadic idiopathic bradykinin angiooedema. Allergy. 2010;65(6):793-5.

33.Gonzalez P, Soriano V, Caballero T, Niveiro E. Idiopatic angiooedema treated with dapsone. Allergol Immunopathol (Madr). 2005;33(1):54-6.

34.Cicardi M, Levy RJ, McNeil DL et al. Ecallantide for the treatment of acute attacks in hereditary angiooedema. N Engl J Med. 2010;363(6):523-31.

35. Craig TJ, Levy RJ, Wasserman RL et al. Efficacy of human C1 esterase inhibitor concentrate compared with placebo in acute hereditary angiooedema attacks. J Allergy Clin Immunol. 2009;124(4):801-8.

36.Zuraw BL, Busse PJ, White $M$ et al. Nanofiltered C1 inhibitor concentrate for treatment of hereditary angiooedema. N Engl J Med. 2010;363(6):513-22.

37.Zuraw B, Cicardi M, Levy RJ et al. Recombinant human C1inhibitor for the treatment of acute angiooedema attacks in patients with hereditary angiooedema. J Allergy Clin Immunol. 2010;126(4):821-827.e14.

38.Thompson RA, Felix-Davies DD. Response of "idiopathic" recurrent angioneurotic ooedema to tranexamic acid. Br Med J. 1978;2(6137):608.

39. Ogston D. Current status of antifibrinolytic drugs. Blood Rev. 1989;3(1):1-4.

40.Sands MF, Blume JW, Schwartz SA. Successful treatment of 3 patients with recurrent idiopathic angiooedema with omalizumab. J Allergy Clin Immunol. 2007;120(4):979-81. 